\title{
Role of Flexible Fiber-Optic Bronchoscopy in the Diagnosis of Lung Cancer
}

\author{
Chauhan $\mathrm{JB}^{1,}$ Patel $\mathrm{BM}^{2 *}$, Patel $\mathrm{P}^{3}$ \\ 1. Associate Professor, Department of Respiratory Medicine, Medical College Baroda, Vadodara \\ 2. Assistant Professor, Department of Respiratory Medicine, Medical College Baroda, Vadodara \\ 3. $3^{\text {rd }}$ year Resident, Department of Respiratory Medicine, Medical College Baroda, Vadodara
}

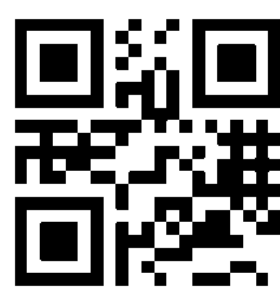

Abstract :

Background: Lung cancer is the leading cause of cancer deaths in the world. Flexible fiber-optic bronchoscopy is the most useful invasive technique for diagnosing lung cancer. Bronchoscopy also useful in staging of cancer. It is also useful in palliative care surgery. Objective: The objective of this study was To study the role of fiber-optic bronchoscopy in diagnosis of lung cancer. Material and Methods : The prospective study was carried out on 50 patients at Department of Pulmonary Medicine, Medical College Baroda, Vadodara. Results: In this syudy total 50 patients were enrolled. Various anatomical types of Endobronchial mass lesion found during bronchoscopy, 22 patients 944\%) had a exophytic mass lesion, 19 patients $(38 \%)$ had a submucosal lesion and 9 patients(18\%) had a peribronchial lesion. We got confirmatory diagnosis in 30 patients so inour study diagnostic yield of bronchoscopy was $60 \%$. Out of 30 diagnosed cases , 15 patients $(30 \%)$ had an adenocarcinoma, 9 patients $(30 \%)$ had a squamous cell carcinoma and 6 patients $(20 \%)$ had a small cell carcinoma, adenocarcinoma more comoon in our study. 25 patients were male and 5 patients were female so lung cancer more common in male than female. Conclusion: In our study we diagnosed 30 patients out of 50 patients for confirm lung malignancy so diagnostic yield of bronchoscopy was $60 \%$. Adenocarcinoma of lung is more common type of lung malignancy in our study and male having a more lung cancer than female.

Key words: Lung Cancer, Bronchoscopy, Forceps biopsy

*Corresponding Author

Dr. Bhavesh M Patel

E-mail id: dr.bhavesh0705@gmail.com

Copyright: This is an open-access article distributed under the terms of the Creative Commons Attribution license which permits unrestricted use, distribution, and reproduction in any medium for non-commercial use (Non Commercial, or CC-BY-NC) provided the original author and source are credited.

\section{INTRODUCTION}

The first bronchoscopy was performed by Gustav Killian of Freiburg in Germany in 1887 . $^{1}$ In initial time bronchoscopy mostly used for therapeutic purpose but after some years in 1960 Fiber-optic bronchoscopy developed by $\mathrm{S}$. lkeda. ${ }^{2}$ Now a day fiber- optic bronchoscopy is a routine procedure in department of Respiratory Medicine but underutilized in rural and remote area in India and in such areas patients still managed without confirmation of diagnosis. Bronchoscopy is considered an useful tool in the diagnosis and therapy of various pulmonary disease like lung cancer, tuberculosis, pneumonia. ${ }^{3-6}$ Many times in rural areas due to lack of availability of bronchoscopy or absence of specialist, any radiological opacity related to lung cancer not resolved with antibiotics considered because of tuberculosis and put on empirical anti TB drug so proper diagnosis is delayed. The flexibility of the bronchoscope allows to inspect the majority of fourth order and often up to sixth order bronchi. Fiber-optic bronchoscopy is safe with a complication rate of $0.12 \%$ and a mortality rate of $0.04 \% .^{7}$ Lung malignancy is the main cause of cancer related mortality in world. ${ }^{8}$ For lung cancer overall 5 year survival is low, as many patients diagnosed at late stage. Patients diagnosed in early stage have a 5 year survival rate more than $70 \%$, so screening and detection of early lung cancer is important to improve in survival rate. ${ }^{9}$ Bronchoscopy is useful tool in early diagnosis and confirmation of diagnosis so with help of fiber-optic bronchoscopy we can diagnose lung cancer early and improve 5 year survival rate. The objective of present work to study the role of bronchoscopy in diagnosis of lung cancer and study the various histological type of lung cancer

\section{MATERIALS AND METHODS}

This prospective study carried out at SSG hospital Vadodara attached to Medical college Baroda. In this study total 50 patients were involved. Those patients who had a clinical symptom and radiological finding suggestive of 
suspected lung malignancy, all of them underwent contrast enhanced CT scan for confirmation of diagnosis and site location of lesion. Those patients involved in study, Who had a central lesion or Endobronchial lesion in CT scan. Inclusion Criteria: On clinical and radiological findings suggest a suspicious lung malignancy and contrast enhanced CT scan suggestive of central lesion or Endobronchial lesion. Exclusion criteria: 1.Patient having pulmonary and cardiovascular risk factor 2 . Patient at high risk of bleeding 3. Unwilling for bronchoscopy.

\section{RESULTS}

In this study total 50 patients were enrolled, all of them underwent for bronchoscopy. Various types anatomical types of Endobronchial mass lesion found during bronchoscopy as shown in table no. 1. 22 patients (44\%) had a Exophytic mass lesion, 19 patients (38\%) had a submucosal lesion and 9 patients (18\%) had a peribronchial lesion. We done a bronchoscopy in 50 patients and taken forceps biopsy in all patients but we got confirmatory histopathological diagnosis of lung malignamcy in 30 patients, so in our study yield of bronchoscopy in diagnosis of lung cancer was $60 \%$. As shown in Table No. 2, we found 22 patients had an exophytic mass lesion during bronchoscopy, out of them 15 patients (68.2\%) diagnosed for lung malignancy, we found 19 patients had a submucosal lesion during bronchoscopy, out of them 9 patients (47.3\%) diagnosed for lung malignancy, we found 9 patients had a peribronchial lesion, out of them 6 patients $(66.6 \%)$ diagnosed for lung malignancy. We got confirmatory diagnosis in 30 patients, Out of them 15 patients $(50 \%)$ had a Adenocarcinoma, 9 patients $(30 \%)$ had a Squamous cell carcinoma and 6 patients (20\%) had a small cell carcinoma, as shown in Table No.3. So in our study most common diagnosed lung malignancy was adenocarcinoma. Total 15 patients of exophytic mass lesions were diagnosed, out of them 10 patients had a adenocarcinoma, 2 patients had squamous cell carcinoma and 3 patients had a small cell carcinoma. Total 9 patients of submucosal mass lesion were diagnosed, out of them 4 patients had a adenocarcinoma, 4 patients had a squamous cell carcinoma and 1 patients had a small cell carcinoma. Total 6 patients of peribronchial mass lesion were diagnosed out of them, 1 patient had a adenocarcinoma, 3 patients had squamous cell carcinoma, 2 patients had a small cell carcinoma. Total 30 cases were diagnosed out of them 25 patients were male and 5 patients were female.

Table 1: Anatomical type of Endobronchial mass lesion.
\begin{tabular}{|l|c|c|}
\hline $\begin{array}{l}\text { Types of Endobronchial } \\
\text { mass lesion }\end{array}$ & No. of cases & Percentage \\
\hline Exophytic mass lesion & 22 & 44 \\
\hline Submucosal lesion & 19 & 38 \\
\hline Peribronchial lesion & 9 & 18 \\
\hline Total & 50 & 100 \\
\hline
\end{tabular}

Table 2: Diagnostic yield of forceps biopsy in Endobronchial mass lesion

\begin{tabular}{|l|l|l|l|l|}
\hline Methods & $\begin{array}{l}\text { EML } \\
\text { N=22 }\end{array}$ & $\begin{array}{l}\text { SML } \\
\text { N=19 }\end{array}$ & $\begin{array}{l}\text { PML } \\
\text { N=9 }\end{array}$ & $\begin{array}{l}\text { TOTAL } \\
\text { N=50 }\end{array}$ \\
\hline $\begin{array}{l}\text { Forceps } \\
\text { Biopsy }\end{array}$ & 15 & 9 & 6 & 30 \\
& $(68.2 \%)$ & $(47.3 \%)$ & $\begin{array}{l}6 \\
(66.6 \%)\end{array}$ & $(60 \%)$ \\
\hline
\end{tabular}

Table 3: Classification based on histological types of Lung cancer.

\begin{tabular}{|l|c|c|}
\hline Lung Malignancy & No. of cases & Percentage \\
\hline Adenocarcinoma & 15 & 50 \\
\hline Squamous cell carcinoma & 9 & 30 \\
\hline Small cell carcinoma & 6 & 20 \\
\hline Total & 30 & 100 \\
\hline
\end{tabular}

Table 4: Anatomical variants and histological types in lung cancer

\begin{tabular}{|c|c|c|c|c|}
\hline Type of Lung cancer & $\begin{array}{l}\text { EML } \\
\text { N=15 }\end{array}$ & $\begin{array}{l}\text { SML } \\
\mathbf{N}=9\end{array}$ & $\begin{array}{l}\text { PBL } \\
N=6\end{array}$ & Total \\
\hline Adenocarcinoma & 10 & 4 & 1 & 15 \\
\hline Squamous cell carcinoma & 2 & 4 & 3 & 9 \\
\hline Small cell carcinoma & 3 & 1 & 2 & 6 \\
\hline \multicolumn{5}{|c|}{ Table 5: Gender and Lung cancer } \\
\hline & MALE & \multicolumn{2}{|c|}{ FEMALE } & Total \\
\hline Adenocarcinoma & 13 & \multicolumn{2}{|c|}{ 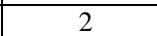 } & 15 \\
\hline Squamous cell carcinoma & 7 & \multicolumn{2}{|c|}{2} & 9 \\
\hline Small cell carcinoma & 5 & \multicolumn{2}{|c|}{1} & 6 \\
\hline
\end{tabular}

\section{DISCUSSION}

Lung cancer is leading cause of death in world related to cancer death. ${ }^{9}$ Early diagnosis help in improvement in 5 year survival rate in lung cancer patients. In our study diagnostic yield of bronchoscopy was $60 \%$ in diagnosis of lung cancer. In our study we used only forceps biopsy, but we can improve diagnostic yield of bronchoscopy by using latest modalities like endo bronchial ultrasound (EBUS), Transbronchial needle aspiration cytology (TBNA), cryo biopsy. In our study adenocarcinoma of lung is more common than other type of malignancy. Male were more affected than female. In Kshatriya et al, diagnostic yield of bronchoscopy was 68\% through BAL cytology, brush cytology and bronchoscopy guided biopsy. ${ }^{10}$ Squamous cell carcinoma (44\%) more common in this study as in our study adenocarcinoma was more common. Male were more common affected in this study as in our study also male were more common affected. 
CONCLUSION

In our study total 50 patients were enrolled out of the 30 patients were diagnosed so the yield of fiber-optic bronchoscopy was $60 \%$. Adenocarcinoma was more common type of lung cancer and male were more affected than female

Conflicts of interest: Declared, authours have no conflict of interest

Funding/Financial support: None

\section{REFERENCES}

1. Killian G. Ueber directe Bronchoscopie. MMW $1898 ; 27 ; 844-847$

2. Jackson Ch. The life of chevalier Jackson. An autobiography. New York, Macmillan, 1938

3. Alzeer AH, Al-Otair HA, Al-Hajjaj MS, Yield and Complication of flexible fiberoptic bronchoscopy in a teaching hospital Saudi Med J 2008 ; 29(1) ; 477-481

4. Gasparini S. Bronchoscopic biopsy techniques in the diagnosis and staging of lung cancer. Monaldi Arch Chest Dis 1997 ; $52 ; 392-8$.

5. Elston WJ, Whittaker AJ, Khan LN, Floodpage P, Ramsay C, Jeffery PK, et al. Safety if research bronchoscopy, biopsyand bronchoalveolar lavage in asthma. Eur Respir J 2004 ; 24; 375-7

6. Ouellette DR. The safety of bronchoscopy in a pulmonary fellowship program. Chest 2006; $130 ; 1185-90$

7. Becker HD, shirakawa T, Tanaka F, et al. Transbronchial lung biopsyin the immunocompromised patient. Eur Respir Mon 1998; 9; 193-208.

8. Siegel R, Ward e, Brawley O, et al. Cancer statistics, 2011 ; the impact of eliminating socioeconomic and racial disparities on premature cancer deaths. CA Cancer J Clin $2011 ; 61 ; 212-36$

9. Allemani C, Weir HK, Carreira $\mathrm{H}$, et al. Global surveillance of cancer survival 19952009 ; analysis of individual data for 25,676,887 patients from 279 populationbased registries in 67 countries (CONCORD-2). Lancet 2015 ; 385 ; 9771010. 10. 1016/S0140-6736 (14) 62038-9

10. Kshatrya RM, Khara NV, Paliwal R, Patel $\mathrm{S}$, Role of flexible fiber-optic bronchoscopy in the diagnosis of pulmonary diseases in rural based tertiary hospital. Int $\mathrm{J}$ MedSci Public Health. 2016; 5(5): 873-876. 